\title{
A Study of Platelet-Relevant Parameters in Patients with Diabetic Microangiopathy
}

\author{
M. Porta*, A. M. Peters, S. A. Cousins, E. Cagliero, M. L. FitzPatrick and E. M. Kohner \\ Departments of Medicine, Haematology and Medical Physics, Hammersmith Hospital and Royal Postgraduate Medical School, London, UK
}

\begin{abstract}
Summary. In 16 diabetic patients with microangiopathy, survival of ${ }^{111} \mathrm{In}-\mathrm{lab}$ lled autologous platelets, mean platelet volume, megathrombocyte index, spontaneous and ADP-induced platelet aggregation, platelet retention, $\beta$-thromboglobulin, von Willebrand factor and factor VIII-related antigen were measured; the splenic uptake of radioactive label was quantitated in six patients. Compared with normal subjects, increased platelet aggregation $(p<0.01)$, von Willebrand factor $(p<0.02)$ and factor VIII-related antigen $(p<0.02)$ were observed. Platelet survival was shortened in two patients. It correlated inversely with the splenic radioactivity uptake ( $r=-0.95 ; p<0.01$ ), suggesting that platelets ended their life
\end{abstract}

in the spleen, not in the microcirculation. No significant relationships were found between the various tests performed, nor between these and the severity of microangiopathy or other clinical data. In spite of the evidence for altered platelet function in patients with diabetic microangiopathy, currently available tests are not specific enough to clarify the nature of these changes or their possible pathogenic significance.

Key words: Diabetic microangiopathy, platelet aggregation, platelet adhesiveness, platelet function, $\beta$-globulins, blood coagulation factors.
Several reports have indicated that blood platelets and endothelial cells behave abnormally in patients with diabetic microangiopathy $[1,2]$, but the pathogenetic significance of these changes is unknown. Platelet/vessel wall interactions cannot be studied in vivo and most investigative procedures are carried out on blood components isolated from their environment. These procedures are useful for physiological and pharmacological investigations but it is not known to what extent the phenomena observed in vitro reflect events occurring in life. In this study, several tests of platelet function were performed simultaneously in 16 patients with diabetic microangiopathy, to establish whether abnormal results of procedures in vitro (a) agree with each other in indicating altered platelet function, (b) are associated with shortened platelet survival and/or increased plasma levels of the endothelial synthesized von Willebrand factor, and (c) reflect the severity of vascular damage.

\section{Patients, Materials and Methods \\ Patients}

Fifteen male and one female diabetic patients with a mean age of 52 years (range: $28-74$ years) and mean duration of disease of 21 years

\footnotetext{
* Present address: Istituto Unificato di Medicina Interna, Cattedra di Endocrinologia, Corso Polonia 14, I-10126 Torino, Italy
}

(range: 8-38 years) gave their informed consent in accordance with the Declaration of Helsinki (1975). The protocol had been approved by the Hospital Ethical Committee. Ten patients were on insulin therapy and six on oral hypoglycaemic agents. Mean percentage desirable body weight, calculated according to the middle of the weight range for subjects of medium frame from the 1959 Metropolitan Life Insurance Company Tables [3], was 120\% (range: 100-158\%). Eleven patients were admitted to the Hospital for 8 days and five attended daily for blood collections on an outpatient basis. No patient had taken aspirin or other non-steroidal anti-inflammatory drugs, apart from paracetamol, for at least 15 days before the study. All the patients had diabetic microangiopathy. Two had background retinopathy, defined by the presence of microaneurysms, retinal haemorrhages, hard exudates and cotton wool spots. Three had visual impairment due to macular oedema or hard exudates, indicating maculopathy. Proliferative retinopathy, indicated by new vessels and/or fibrous tissue was present in 11 patients. Two patients had been treated previously by pituitary ablation. Hypertension, defined as blood pressure values measured repeatedly above $160 / 95 \mathrm{mmHg}$ for at least 1 year, was found in six patients. Four patients had nephropathy, as indicated by persistently raised blood urea $(>6.5 \mathrm{mmol} / \mathrm{l})$ as well as creatinine $(>125 \mathrm{mmol} / \mathrm{l}$ ) and/or proteinuria (Albustix) on repeated occasions for at least 1 year. Twelve patients had diabetic neuropathy, as evaluated by reduced or absent knee and ankle reflexes, vibratory sense, postural hypotension and impotence on at least two consecutive yearly assessments. Claudication, indicated by absent foot pulses and subjective symptoms, was present in six patients. One patient had bilateral carotid bruit, one had angina and one suffered from inactive ankylosing spondilytis and a recent episode of left retinal branch vein occlusion. Three patients were treated for hypertension: one by bendrofluazide, one by alpha-methyldopa, propranolol and bendrofluazide, and one by atenolol. 
Table 1. Normal ranges and reproducibility of the techniques for platelet survival, volume, retention, $\beta$-thromboglobulin, von Willebrand factor and factor VIII-related antigen

\begin{tabular}{llllll}
\hline Test & $\begin{array}{l}\text { Num- } \\
\text { ber } \\
\text { of } \\
\text { obser- } \\
\text { vations }\end{array}$ & $\begin{array}{l}\text { Mean } \pm \\
\text { SEM }\end{array}$ & $\begin{array}{l}\text { Normal } \\
\text { range }\end{array}$ & $\begin{array}{l}\text { Intra-assay Inter- } \\
\text { coefficient } \\
\text { of } \\
\text { variation } \\
(\%)\end{array}$ & $\begin{array}{l}\text { assay } \\
\text { coeffi- } \\
\text { cient of } \\
\text { variation } \\
(\%)\end{array}$ \\
\hline $\begin{array}{c}\text { Platelet survival } \\
\text { (days) }\end{array}$ & 8 & 9.5 & $9.2-9.9^{\mathrm{a}}$ & - & - \\
$\begin{array}{c}\text { Mean platelet } \\
\text { volume (fl) }\end{array}$ & 30 & $10.9 \pm 0.2$ & $8.7-13.1$ & 1.9 & 2.7 \\
$\begin{array}{c}\text { Megathrom- } \\
\text { bocyte } \\
\text { index (fl) }\end{array}$ & 30 & $22.2 \pm 0.4$ & $17.8-26.6$ & 2.2 & 2.5 \\
$\begin{array}{c}\text { Platelet } \\
\text { retention (\%) } \\
\beta \text {-thrombo- } \\
\text { globulin } \\
\text { (ng/ml) }\end{array}$ & 20 & $30.5 \pm 1.8$ & $14-47$ & 28.1 & - \\
$\begin{array}{c}\text { von Willebrand } \\
\text { factor (\%) }\end{array}$ & 30 & $103 \pm 7$ & $59-196$ & 19.5 & 21.3 \\
$\begin{array}{c}\text { Factor-VIII- } \\
\text { related } \\
\text { antigen (\%) }\end{array}$ & 33 & $100 \pm 7$ & $26-200$ & 5.2 & 13.1 \\
\hline
\end{tabular}

a $95 \%$ confidence limits; ${ }^{b}$ geometric mean

\section{Blood Collections}

Blood samples were collected in the afternoon of day 0 of the survival curves. Blood for $\beta$-thromboglobulin was always collected first, without stasis, using a $21-\mathrm{G}(0.8 \mathrm{~mm})$ disposable needle and a $5 \mathrm{ml}$ plastic syringe. The blood was immediately transferred into a chilled plastic tube containing an EDTA-theophylline mixture (Radiochemical Centre, Amersham, Bucks, UK), mixed by three gentle inversions and placed into a wet crushed ice bath.

The other samples were collected in plastic syringes by a $19-\mathrm{G}$ $(1.1 \mathrm{~mm})$ butterfly needle inserted into an antecubital vein of the opposite arm. Blood for platelet labelling $(42.5 \mathrm{ml})$ was taken into a syringe containing $7.5 \mathrm{ml}$ of sterile acid citrate dextrose (National Institutes of Health, formula A). Blood for platelet volume $(5 \mathrm{ml})$ was collected into plastic tubes containing EDTA to give a final concentration of $1.5 \mathrm{mg} / \mathrm{ml}$. Blood $(9 \mathrm{ml})$ was mixed with $1 \mathrm{ml}$ of $3.13 \%$ trisodium citrate for the assessment of in vitro platelet aggregation and plasma levels of von Willebrand factor and factor VIII-related antigen. Non-anticoagulated blood $(5 \mathrm{ml})$ was used for platelet retention tests.

\section{Methods}

Platelets were labelled by a method described previously [4]. In brief $300 \mu \mathrm{Ci}$ of ${ }^{111}$ Indium ${ }^{111} \mathrm{In}$ ) Amersham International, Bucks, UK) were incubated for $5 \mathrm{~min}$ with autologous platelets resuspended in Hepes saline (pH 7.6) containing acetylacetone 0.19\% (Sigma Chemicals, St. Louis, Missouri, USA). Having removed the unbound label, the platelets were re-suspended in the patient's own plasma and injected intravenously. As the labelling efficiency of the method was about $70 \%$, the patients received a dose of about $200 \mu \mathrm{Ci}$.

Blood samples ( $5 \mathrm{ml}$ in $1.5 \%$ EDTA) were taken daily over the following week. Aliquots of $1 \mathrm{ml}$ whole blood and $1 \mathrm{ml}$ platelet poor plasma (PPP) were counted in a gamma counter (Packard, Model 5360, Downers Grove, Illinois, USA) and the platelet bound-activity calculated by the formula:

Platelet activity $=$ whole blood activity $-(1-$ packed cell volume) $\times$ PPP activity.

The results were plotted against time and platelet survival calculated by a best-fit line. The fraction of ${ }^{111}$ In dose present in the spleen at days $0,3,4,5$ and 6 was quantitated by the method of Williams et al. [5] in six patients, using a double-headed rectilinear scanner (Ohio Nuclear, Model 84, Cleveland, Ohio, USA). 'Pooled' ${ }^{111}$ In, (i. e. the radionuclide on platelets pooled in the spleen) and 'fixed' ${ }^{111}$ In (i. e. the radionuclide in splenic tissue following intrasplenic platelet destruction) were distinguished as follows. Since circulating platelets pool in the spleen [6], the splenic radioactivity measured on day 0 , within $1 \mathrm{~h}$ of platelet injection, is almost entirely due to pooled platelets. This pooled ${ }^{111}$ In signal subsequently declines in parallel with the blood platelet activity level and can therefore be estimated as a fraction of the splenic activity level on day 0 . The difference between the pooled and the total splenic activity is therefore the 'fixed' ${ }^{111}$ In level [7]. Platelet volume distribution was assessed by a Coulter Counter ZBI (Coulter Electronics, Luton, Beds, UK) attached to a Coulter Channelizer C-1000 (Coulter Electronics), using a method previously described $[8,9]$. The following settings were used: Coulter counter: aperture current $=0.177$; amplification $=1$; lower threshold $=5$; upper threshold $=85$; Channelizer: base channel threshold $=5$; window width $=100$; upper limit of accumulation $=4,000$.

The resulting platelet volume distribution curve was analysed using a computer (Hewlett-Packard, Model $9801 \mathrm{~A}$, Palo Alto, California, USA) and a plotter (Hewlett-Packard, Model 9862 A), volumes in $\mathrm{fl}$ being on the horizontal axis and relative volume frequencies on the vertical axis. The parameters measured were the mean platelet volume and the megathrombocyte index. The latter was calculated according to Karpatkin [10] on the coordinate of the horizontal axis where the tenth percentile of the vertical axis transected the descending limb (right side) of the volume distribution curve. Mean platelet volume and megathrombocyte index were expressed in fl. The system was checked for electronic drift using a batch of glutaraldehyde-fixed human red cells [11]: no up- or downward trend was observed for the relevant mean volume throughout the period of study.

ADP-induced platelet aggregation was assessed as previously described by determining the minimum (threshold) concentration of this agent able to induce irreversible aggregation of citrated platelet-rich plasma [12]. ADP was used in final concentrations of $0.4,1.2,2.0$ and $10.0 \mu \mathrm{mol} / 1$. The occurrence of spontaneous aggregation was determined by stirring the platelet-rich plasma $(250 \mu \mathrm{l}$ at $1,100 \mathrm{rev} / \mathrm{min})$ at $37^{\circ} \mathrm{C}$ for $10 \mathrm{~min}$ in a dual Channel Payton aggregometer (Payton Associates, Buffalo, New York, USA).

Platelet retention in glass bead columns was measured as previously described in non-anticoagulated native blood immediately after venepuncture [13]. Commercial kits (Adeplat T columns and Adeplat pump, Semmelweis, Milan, Italy) were used. Platelet counts were performed by the Coulter counter on specimens collected before $\left(C_{100}\right)$ and after $\left(C_{X}\right)$ passage of blood through the glass beads. Retention was calculated according to the formula:

$\frac{\mathrm{C}_{100}-\mathrm{C}_{\mathrm{X}}}{\mathrm{C}_{100}} \times 100$.

$\beta$-thromboglobulin was measured in $\mathrm{ng} / \mathrm{ml}$ by commercial kits (Radiochemical Centre, Amersham, Bucks, UK). Von Willebrand factor (vWF) was measured as previously described by ristocetin-induced agglutination of fixed washed platelets [14]. Factor VIII-related antigen (VIII-RAG) was measured by immunoelectrophoresis using Laurell's technique [15]. Both vWF and VIII-RAG are expressed as percentage activity compared with a standard plasma pooled from 20 healthy donors, defined as a $100 \%$ activity.

\section{Statistical Analysis}

Survival curves were expressed in days and as $95 \%$ confidence limits. The latter were calculated for the slope of the regression line (i.e. $\mathrm{B} \pm \mathrm{b})$ and the zero time intercept (i.e. $\mathrm{A} \pm \mathrm{a}$ ). The $95 \%$ confidence interval for survival time was taken as: $\frac{(A+a)}{(B+b)}$ to $\frac{(A-a)}{(B-b)}$. Normally distributed parameters were expressed as mean \pm SEM. Non-symmetrically distributed parameters were indicated as geometric means and range. Statistical calculations were carried out by Student's t-test and, where appropriate, by Wilcoxon's or chi-square test. Coefficients of correlation were obtained from linear regression analysis. 


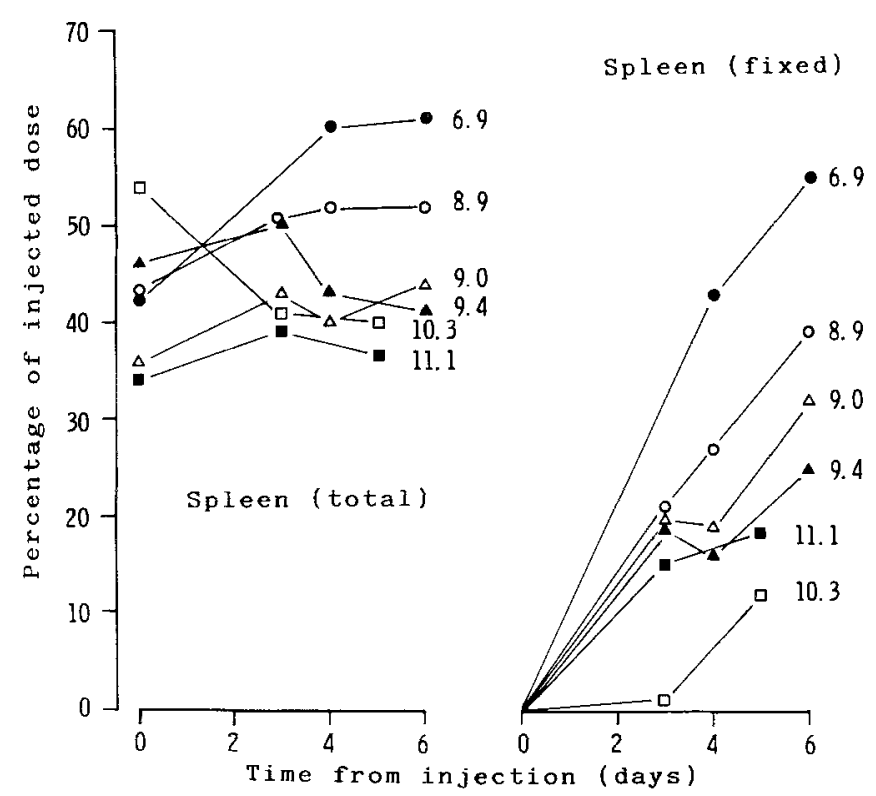

Fig. 1. Splenic retention (percentage of total and 'fixed' dose of ${ }^{111} \mathrm{In}$ injected) in six patients with diabetic microangiopathy. Quantitative scanning was carried out on days $0-6$ of the survival curves. Figures on the right of diagrams indicate platelet survival times (in days) for each patient

Normal ranges for the various tests employed were determined in groups of healthy subjects similar to the patients of this study by age and body weight. These are shown in Table 1 together with the relevant reproducibilities. ADP-induced aggregation had been determined in 24 controls: one of these $(4 \%)$ aggregated with $0.4 \mu \mathrm{mol} / \mathrm{l}$, six $(25 \%)$ with $1.2 \mu \mathrm{mol} / 1$, eight $(33 \%)$ with $2.0 \mu \mathrm{mol} / 1$ and nine $(38 \%)$ with $10.0 \mu \mathrm{mol} / \mathrm{l}$. The same ADP threshold was reproducible on $80 \%$ of occasions in the same platelet-rich plasma. Spontaneous aggregation was rarely observed in control subjects.

\section{Results}

The patients as a group showed a lower ADP threshold for aggregation $(p<0.01)$ and increased plasma levels of vWF $(132 \pm 9 \% ; p<0.02)$ and VIII-RAG $(132 \pm 10 \%$; $p<0.02)$ when compared with normal values. Irreversible aggregation was induced by ADP $(0.4 \mu \mathrm{mol} / 1)$ in platelet-rich plasma from three patients $(19 \%)$, by ADP $(1.2 \mu \mathrm{mol} / \mathrm{l})$ in 11 patients $(69 \%)$ and by ADP $(2.0 \mu \mathrm{mol} / \mathrm{l})$ in two patients $(12 \%)$. Six patients showed spontaneous aggregation. VWF and VIII-RAG were above the normal range in one patient only.

The average platelet survival was normal ( 9.4 days, 95\% confidence limits $=9.1-9.7$ days), being shortened in two patients only. All the disappearance curves were linear. Survival correlated inversely with total splenic radioactivity uptake $(r=-0.95, p<0.01)$ as well as with fixed splenic radioactivity $(r=-0.94, p<0.01)$ at days 5-6 (Fig. 1). Mean values of platelet volume $(11.3 \pm 0.5 \mathrm{fl})$, megathrombocyte index $(21.9 \pm 1.0 \mathrm{fl})$, platelet retention $(30 \pm 3 \%)$ and $\beta$-thromboglobulin (geometric mean $=39 \mathrm{ng} / \mathrm{ml}$; range: $23-62 \mathrm{ng} / \mathrm{ml}$ ) did not differ from the relevant normal ranges. In two patients the mean platelet volume and the megathrombocyte index were above the normal range; in one patient these parameters were lower. The mean platelet volume correlated with the megathrombocyte index $(r=0.98$, $p<0.001)$ and vWF correlated with VIII-RAG $(r=0.72$, $p<0.001$ ). Apart from these, no relationships were found between any of the haemostatic parameters measured, nor between these and the clinical features of the patients. In individual patients results outside the normal range were not necessarily associated with other haemostatic abnormalities. One patient, who had abnormally low mean platelet volume and megathrombocyte index but no other abnormalities, developed an arterial embolus 1 year after the study, which led to amputation of his right leg. Another patient, who had the shortest platelet survival as well as spontaneous aggregation in vitro, suffered from ankylosing spondilytis and from a recent retinal branch vein occlusion, but had only mild background retinopathy in the other eye.

\section{Discussion}

The determination of platelet kinetics by radioactive labelling represents the only possible approach to the study of platelet behaviour in life. ${ }^{111}$ Indium is considered the best available isotope for this purpose. It binds strongly to intracellular receptors with negligible elution [16], has a half-life of 2.8 days, which is ideal for platelet studies, and labels cells very efficiently without loss of function [17, 18]. Furthermore, since it is a good gamma-emitter, it is possible to detect and quantitate the sequestration of platelets in the spleen and liver [7, $18]$.

In spite of these properties, ${ }^{111}$ Indium has not been used in studies of platelet kinetics in diabetes. Using ${ }^{51} \mathrm{Cr}$ and ${ }^{75}(\mathrm{Se})$-seleniomethionine, other authors have reported shortened platelet half-life and/or exponential disappearance curves (suggestive of random destruction superimposed on linear age-related disappearance) in some patients with and without vascular complications [19-22]. In this study two subjects had shortened survival times but the mean of the 16 patients was normal. All the disappearance curves were linear; this discrepancy may therefore reflect the use of different radio-labels. In fact ${ }^{51} \mathrm{Cr}$ may disappear exponentially even from the circulation of normal subjects, possibly as a result of elution from the platelets [23] or failure to count only cell-bound, as opposed to total blood, activity. The strict correlation found between platelet survival and splenic radioactivity uptake provides further evidence that, in patients with diabetic microangiopathy, platelets are not randomly destroyed in the peripheral circulation but end their life in the spleen. Increased splenic sequestration, as observed in two subjects, may reflect removal of platelets altered as a result of interactions with the damaged vessel wall, or with immune complexes [24].

It has been suggested that accelerated platelet turnover results in an increased rate of circulating giant elements or megathrombocytes [25], but survival and vol- 
ume have never been measured in the same diabetic patients. Of 15 patients with retinopathy studied by Garg et al. [26], seven had an elevated percentage of megathrombocytes when assessed by manual counts, but only two were elevated using the Coulter counter. Previous work from this laboratory showed increased mean platelet volume and megathrombocyte index in patients with retinopathy but also demonstrated considerable overlap between the 30 normal and 87 diabetic subjects [9]. In the present study, the volume of platelets was increased in only two of 16 patients and did not correlate with platelet survival. In another report of platelet volume in diabetes, Colwell et al. [27], using a manual method, reported an increased percentage of megathrombocytes in 22 of 44 patients with frank diabetes. The increase in size was associated with in vitro hyperaggregation in response to ADP. Platelet hypersensitivity to ADP was found in the patients of this study, but neither a low ADP threshold $(0.4 \mu \mathrm{mol} / \mathrm{l})$ nor spontaneous aggregation were associated with increased platelet volume or shortened survival. Enhanced platelet aggregation in vitro has been described by several workers [28-30], but not by others [31, 32]. In an earlier report, we were unable to detect hyperaggregation in 30 patients with retinopathy [12]. The same methodology was used as in the present survey, suggesting that discrepancies in these studies may depend on the choice of patients, particularly when small populations are investigated.

The measurement of platelet retention in glass bead columns is a crude test which has yielded conflicting results when applied to diabetic patients [28, 33, 34]. A number of technical details may influence the outcome [35] and the results of most studies cannot be directly compared. Barrantes et al. [36], using the same commercial system as in this work, showed increased retention in a group of 44 diabetic subjects, while none of our patients demonstrated abnormalities of this parameter; this discrepancy may be due to the lower normal range observed by Barrantes.

$\beta$-thromboglobulin, a platelet-specific protein released during aggregation, is considered a sensitive indicator of platelet activation in vivo [37]. Previous studies of diabetic groups have unanimously reported increased mean plasma levels of this protein, as measured by the Amersham kit [38-40]. However, considerable overlap between control and diabetic populations has been reported by all these authors. Our normal range of $\beta$-thromboglobulin is similar to that reported by others [39] and not symmetrically distributed. The geometric mean of the diabetic population was higher than normal (Table 1) but, due to the high levels measured in some controls, the difference was not statistically significant. It is to be noted that hyperaggregation in vitro was not accompanied by high levels of $\beta$-thromboglobulin.

The patients in this study had increased plasma levels of vWF/VIII-RAG, in accordance with all the reports in the literature $[29,41,42]$. We have previously shown that increased vWF/VIII-RAG levels are associated with breakdown of the blood-retinal barrier and may be an indicator of widespread endothelial damage in diabetes [43], but the possible relevance of these raised levels to platelet function has not been established. In the absence of this factor platelets do not adhere to vascular subendothelium [44] or to glass surfaces [45]. Our patients had high vWF/VIII-RAG levels but normal platelet retention in glass bead columns, while their only other abnormality was hyperaggregation in vitro. We have shown previously that, both in normal and diabetic subjects, unidentified anti-adhesive mechanism(s) may counteract the pro-adhesive activity of vWF and that spontaneous and ADP-induced platelet aggregation are not influenced by an acute increase in plasma vWF/VIII-RAG [13, 46]. Therefore, in this study, hyperaggregation and high vWF/VIII-RAG were probably two independent abnormalities.

There was no association between the clinical features of the patients and the results of any haemostatic test. One patient developed a severe thromboembolic episode one year after this study, but the only abnormality detected was decreased platelet volume. Another diabetic patient, who suffered from ankylosing spondylitis and retinal branch vein occlusion, had shortened platelet survival and spontaneous aggregation in vitro. Although it cannot be established if any of these disease states contributed to his platelet abnormalities, it is noteworthy that this patient had the mildest retinopathy of the whole group.

In conclusion, this study shows that, in patients with diabetic microangiopathy, hyperaggregation in vitro and high levels of vWF/VIII-RAG are not accompanied by any evidence of shortened platelet survival or hyperactivity in vivo. Primary haemostasis is certainly altered in some of these patients but currently available tests do not agree with each other in indicating the presence of abnormalities. These procedures are of limited clinical value and are not sufficiently specific to clarify the nature of these changes or their pathogenetic significance. It should be stressed that, to date, no rationale exists for the use of anti-aggregating drugs in diabetic microangiopathy and this medication should be withheld, at least until the results of double-blind placebocontrolled studies now in progress [47, 48] become available.

Acknowledgements. We are indebted to Mrs. H.J. Reavy for excellent technical assistance. This work was supported by the British Heart Foundation (Grant BHF 821), the British Diabetic Association and the Department of Health and Social Security.

\section{References}

1. Bern MM (1978) Platelet function in diabetes mellitus. Diabetes 27: $342-352$

2. Colwell JA, Halushka PV, Sarji KE, Levine J, Sagel J, Nair RMG (1976) Altered platelet function in diabetes mellitus. Diabetes 25 (Suppl 2): 826-831

3. Diem K, Lentner C (eds) (1970) Desirable body weight of adults. Scientific Tables. TR Geigy, Basel, p 712 
4. Peters AM, Lavender JP (1982) Factors controlling the intrasplenic transit of platelets. Eur J Clin Invest 12: 191-195

5. Williams ED, Merrick MV, Lavender JP (1975) The distribution and dosimetry of ${ }^{111}$ Indium-bleomycin in man. Br J Radiol 48: 275-278

6. Peters AM, Klonizakis I, Lavender JP, Lewis SM (1980) Use of ${ }^{111}$ In labelled platelets to measure spleen function. $\mathrm{Br} \mathrm{J}$ Haematol 46: 587-593

7. Klonizakis I, Peters AM, FitzPatrick ML, Kensett MJ, Lewis SM, Lavender JP (1980) Radionuclide distribution following injection of ${ }^{111}$ In labelled platelets. Br J Haematol 46:595-602

8. Lewis SM, Wardle J, Cousins SA, Skelly JV (1979) Platelet counting-development of a reference method and a reference preparation. Clin Lab Haematol 1:227-237

9. Cagliero E, Porta M, Cousins AS, Kohner EM (1982) Increased platelet volume in diabetic retinopathy. Haemostasis 12:293-299

10. Karpatkin S (1978) Heterogeneity of human platelets. VI. Correlation of platelet function with platelet volume. Blood $51: 307-316$

11. Lewis SM, Burgess BJ (1966) A stable standard suspension for red cell counts. Lab Pract 15:305-306

12. Porta M, Hilgard P, Kohner EM (1980) Platelet shape change abnormalities in diabetic retinopathy. Diabetologia 18:217-221

13. Porta M, Cagliero E, Kohner EM (1982) Is the pro-adhesive activity of von Willebrand factor counteracted by a physiological inhibitor of platelet adhesiveness? Clin Sci 62: 239-242

14. Porta M, Maneschi F, White MC, Kohner EM (1981) Twenty-four hour variations of von Willebrand factor and factor VIII-related antigen in diabetic retinopathy. Metabolism 30: 695-699

15. Laurell CB (1972) Electroimmunoassay. Scand J Lab Clin Invest 29 (Suppl 124): 21-37

16. Joist JH, Baker RK, Thakum ML, Welch MJ (1978) Indium-111 labelled human platelets: uptake and loss of label and in vitro function of labelled platelets. J Lab Clin Med 92: 829-836

17. Hawker RJ, Hawker LM, Wilkinson AR (1980) Indium-111 labelled human platelets. Optimal method. Clin Sci 58: 243-248

18. Heyns A du P, Lotter MG, Badenhorst PN, van Reenen OR, Pieters H, Minnaar PC, Retief FP (1980) Kinetics, distribution and sites of destruction of ${ }^{111}$ In labelled human platelets. Br J Haematol 44: $269-280$

19. Abrahamsen AF (1968) Platelet survival studies in man (with special reference to thrombosis and atherosclerosis). Scand J Haematol 3 (Suppl): $7-53$

20. Ferguson JC, Mackay N, Philipp JAD, Sumner DJ (1975) Determination of platelet and fibrinogen half-life with $\left({ }^{75} \mathrm{Se}\right)$-seleniomethionine, studies in normal and diabetic subjects. Clin Sci Mol Med 49: 115-120

21. Dassin E, Najean Y, Poirier O, Passa P, Bensoussan D (1978) In vivo platelet kinetics in 31 diabetic patients. Correlation with the degree of vascular impairment. Thromb Haemost 40: 83-88

22. Jones RL, Paradise C, Peterson CM (1981) Platelet survival in patients with diabetes mellitus. Diabetes 30: 486-489

23. Steele P, Rainwater J, Vogel R, Genton E (1978) Platelet suppressant therapy in patients with coronary artery disease. $J$ Am Med Ass 240: 228-231

24. van Zile J, Kilpatrick M, Laimins M, Sagel J, Colwell JA, Virella G (1981) Platelet aggregation and release of ATP after incubation with soluble immune complexes purified from the serum of diabetic patients. Diabetes 30:575-579

25. Garg SK, Amorosi EL, Karpatkin S (1971) Use of the megathrombocyte as an index of the megakaryocyte number. $\mathrm{N}$ Engl $\mathrm{J}$ Med 284: $11-17$

26. Garg SK, Lackner H, Karpatkin S (1972) The increased percentage of megathrombocytes in various clinical disorders. Ann Int Med 77: 361-369

27. Colwell JA, Sagel J, Crook L, Chambers A, Laimins M (1977) Correlation of platelet aggregation, plasma factor activity and megathrombocytes in diabetic subjects with and without vascular disease. Metabolism 26:279-285

28. Heath H, Bridgen WD, Canever JV, Pollock J, Hunter PR, Kelsey $\mathfrak{I}$, Bloom A (1971) Platelet adhesiveness and aggregation in relation to diabetic retinopathy. Diabetologia 7: 308-315
29. Bensoussan D, Levy-Toledano S, Passa P, Caen J, Canivet J (1975) Platelet hyperaggregation and increased plasma levels of von Willebrand factor in diabetics with retinopathy. Diabetologia 11: $733-738$

30. Sagel J, Colwell JA, Crook L, Laimins M (1975) Increased platelet aggregation in early diabetes mellitus. Ann Int Med 82: 733-738

31. Draminski-Petersen H, Gormsen J (1978) Platelet aggregation in diabetes mellitus. Acta Med Scand 203: 125-130

32. Corbella E, Miragliotta G, Masperi R, Villa S, Bini A, de Gaetano G, Chiumello $G$ (1979) Platelet aggregation and antithrombin III in diabetic children. Haemostasis $8: 30-37$

33. Shaw S, Pegrum GD, Wolff S, Ashton WL (1967) Platelet adhesiveness in diabetes mellitus. J Clin Path 20: 845-847

34. Mayne EE, Bridges JM, Weaver JA (1970) Platelet adhesiveness, plasma fibrinogen and factor VIII levels in diabetes mellitus. Diabetologia $6: 436-440$

35. Coller BS, Zucker MB (1971) Reversible decrease in platelet retention by glass bead columns (adhesiveness) induced by disturbing the blood. Proc Soc Exp Biol Med 136: 769-771

36. Barrantes A, Gei O, Saenz GF, Fonseca J, Schosinski K (1980) Valoracion de la retention plaquettaria en la diabetes mellitus del adulto. Acta Med Costarricense 23: 229-234

37. Ludlam CA, Bolton AE, Moore S, Cash JD (1975) New rapid method for diagnosis of deep venous thrombosis. Lancet 2: 259-260

38. Burrows AW, Chavin SJ, Hockaday TDR (1978) Plasma thromboglobulin concentrations in diabetes mellitus. Lancet 1:235-237

39. Matthews JH, O'Connor JF, Hearnshaw JR, Wood JK (1979) Beta thromboglobulin and glycosylated haemoglobin in diabetes mellitus. Scand J Haematol 23: 421-426

40. Betteridge DJ, Zahavi J, Jones NAG, Shine B, Kakkar VV, Galton DJ (1981) Platelet function in diabetes mellitus in relationship to complications, glycosylated haemoglobin and serum lipoproteins. Eur J Clin Invest 11: 273-277

41. Pandolfi M, Almèr L-O, Holmberg L (1974) Increased von Willebrand antihaemophilic factor A in diabetic retinopathy. Acta Ophthalmol 52:823-828

42. Coller BS, Frank RN, Milton RC, Gralnick HR (1978) Plasma cofactors of platelet function: correlation with diabetic retinopathy and haemoglobins $\mathrm{A}_{1 \mathrm{a}-\mathrm{c}}$. Studies in diabetic patients and normal persons. Ann Int Med 88: 311-316

43. Porta M, Townsend C, Clover GM, Nanson M, Alderson AR, McCraw A, Kohner EM (1981) Evidence for functional endothelial cell damage in early diabetic retinopathy. Diabetologia 20 : 597-601

44. Baumgartner HR (1972) Platelet interactions with vascular structures. Thromb Diath Haemorrh 51 (Suppl): 161-176

45. Salzman EW (1963) Measurement of platelet adhesiveness. A simple in vitro technique demonstrating an abnormality in von Willebrand's disease. I Lab Clin Invest 62: 724-735

46. Porta M (1982) Availability of endothelial von Willebrand factor and platelet function in diabetic patients infused with a vasopressin analogue. Diabetologia 23: 452-455

47. Colwell JA, Abraira C, Anderson J, Bingham S, Kwaan H and 10 VA Medical Centers (1981) Antiplatelet agents in diabetic lower extremity vascular disease. A VA cooperative study. Diabetes 30 (Suppl 1): $85 \mathrm{~A}$

48. Scarabin PY, Samama M (1981) Effect of age on ADP-induced platelet aggregation in diabetic and non diabetic subjects. Thromb Res 22: 687-692

Received: 12 August 1982

and in revised form: 25 April 1983

Dr. Massimo Porta

Istituto Unificato di Medicina Interna

Cattedra di Endocrinologia

Corso Polonia 14

I-10126 - Torino

Italy 